\title{
Modeling of a bioreactor for the fermentation of palmwine by Saccaharomyce cerevisiae (yeast) and lactobacillus (bacteria)
}

\author{
Akpa, Jackson Gunorubon. \\ Department of Chemical/Petrochemical Engineering, Rivers State University of Science and \\ Technology, Port-Harcourt, Rivers State, Nigeria
}

\begin{abstract}
A batch reactor model for the fermentation of palm wine to ethanol and acetic acid has been developed. The kinetics of alcohol and acetic acid production from palm wine was carried out in a laboratory scale experimental batch reactor. 1.5 liters of palm wine was reacted with yeast (Saccharomyce cerevisiae) strain for 12 hours for alcohol production, after which bacteria (lactobacillus) was introduced for another 12 hours for acetic acid production. Biomass, ethanol, acetic acid, and glucose concentrations were sampled every 2 hours. A monod type cell growth kinetic model that accounts for product inhibition was used to approximate the fermentation process. Experimental model fitting technique was used to estimate the kinetic parameters in the model. The reactor models developed were a set of coupled ordinary differential equations and were integrated numerically using the $4^{\text {th }}$ order runge kutta technique. The model equations predicted the experimental results of the concentration of substrate utilized, biomass and products produced accurately with a maximum deviation of $0.402 \%$, hence the models were used for the batch reactor simulation. The effects of initial substrate and biomass concentration on reactor efficiency were investigated.
\end{abstract}

Keywords: Fermentation process, palm wine, kinetics and reactor models.

\section{INTRODUCTION}

Fermentation is the metabolic conversion of a carbohydrate such as sugar into an alcohol or an acid using yeast, bacteria or a combination thereof (mixed culture) (Adams, 1995). It is also the slow decomposition of organic substance induced by micro-organisms or by complex nitrogenous substances (Enzymes) of plant and animal origin (Board, 1983). In this process also, starch is broken down into fermentable sugars by fungal enzymes such as alpha amylase and glucoamylase to facilitate fermentation by yeast, mainly saccharomyces species. Fermentation could occur under anaerobic or aerobic conditions and yields lactate, acetic acid, ethanol, carbon dioxide or some other simple product (Esechie, 1979).

The numerous important products obtained by fermentation such as antibiotics, vitamins, feed supplements, and blood plasma expanders, has made fermentation as an industrial method for making specialty and various industrial chemicals gain wide attention (Horold, et al., 1981).

The production of industrial chemicals enhances the economic growth of any nation. Ethanol is one such industrial chemical used diversely as a solvent for chemicals, as an intermediate in the production of liquid detergents, in the manufacture of drugs, plastics, polishes, plasticizers and cosmetics, as antifreeze and as fuel ethanol (Akpan et al., 2005). Ethanol can be produced by Ethylene hydration or Fermentation (Agu et. al., 1993). The production of ethanol by fermentation is applied in this work.

Ethanol can be made by fermentation using a number of renewable feed stocks, including sugar crops such as sugarcane, starch containing grains such as corn, or lignocellulosic materials including agricultural residues, herbaceous crops, and wood (Wang, et al., 2004).

Palm wine has been used locally in Nigeria for ethanol production by rural farmers. Palm wine is an alcoholic beverage obtained from the sap of various species of palm trees and is common in various parts of Africa. In Nigeria, it is abundant in the Niger delta and Rivers state in particular. The sap is extracted and collected by a tapper. Typically the sap is collected from the cut flower of the palm tree. A container is fastened to the flower stump to collect the sap. The white liquid that initially collects tends to be very sweet and non-alcoholic before it is fermented (Okafor, 1990). 
Palm wine (saccharamyces species) has been used for bio-ethanol production at industrial level using different sources of fermentable sugars (Okafor, 1975). The use of Palm wine as the source of fermentable sugar is investigated in this work. This work seeks to study the kinetics of palm wine fermentation, determine the kinetic parameters and develop an appropriate reactor model which is used with the kinetic parameters for studying the fermentation equipment's performance.

The primary objective of a kinetic model is the prediction of the rate (kinetic behavior) of the fermentation process; the development of the corresponding mathematical model for the reactor would be a powerful instrument for predicting/studying equipment performance, solve control problems and permit a rational design of continuous fermentation processes. A reliable and accurate model is also essential for design of large scale ethanol production process.

Experimental methods and materials: This experiment requires a laboratory scale bioreactor, yeast (Saccharomyce Cerevisiae), bacteria (lactobacillus) and fresh palm wine (substrate), as the raw materials. The products obtained were ethanol and acetic acid. The formation of these products is also accompanied by biomass formation (increase in the cell mass of the micro-organisms).

Sample collection - palm wine: Fresh palm wine samples from Raphia palm (Raphia hookeri) were collected in sterile 2.5 litre sample containers from palm wine tapers in kpean community of Khana Local Government area of Rivers State, Nigeria within 30 to 60 minutes of tapping. The sample was immediately transported to the laboratory in iced coolers. The sample was stored at $4^{\circ} \mathrm{C}$ until required for use.

Culture of the micro-organism: The microorganisms (yeast and bacteria) used were cultured at the Microbiology laboratory, Department of Microbiology, Rivers State University of Science and Technology.

Yeast isolates and culture: The yeast were isolated and purified on Potato Dextrose Agar (PDA-Oxoid) by streak plate technique and the purified cultures were maintained on PDA slants at $6^{\circ} \mathrm{C}$. Starter cultures were prepared in $100 \mathrm{ml}$ of sterile culture medium in $250 \mathrm{ml}$ Erlenmyer flasks containing $5 \mathrm{~g}$ glucose; $1 \mathrm{~g}$ peptone and $1 \mathrm{~g}$ yeast extract, buffered at $\mathrm{pH}$ of 4.5 by $0.1 \mathrm{M} \mathrm{KH} \mathrm{KO}_{4}$. A portion of the yeast colony from the PDA slants was picked using a sterile wire loop, inoculated in the culture medium, incubated for 24hours at room temperature $\left(28 \pm 2^{\circ} \mathrm{c}\right)$ and used for fermentation studies.

Lactobacillus isolate and culture: The isolation of these micro-organisms were done using the serial dilution method as described by Harrigan and Mccane (1990). The nutrient broth was prepared as follows: $10 \mathrm{~g}$ bacto-trytone, $5 \mathrm{~g}$ yeast extracts and $10 \mathrm{~g}$ $\mathrm{Nacl}$ was added to $800 \mathrm{ml}$ of water. The $\mathrm{pH}$ of the mixture was adjusted to 7.5 with $\mathrm{NaOH}$, the volume adjusted to $1 \mathrm{~L}$ with distilled water and the mixture sterilized by autoclaving. A portion of the lactobacillus colony was picked using a sterile wire loop and introduced into the nutrient broth. The broth was incubated for 24 hours at $28 \pm 2^{\circ} \mathrm{C}$ and used for fermentation studies.

Experimental procedure: The experiment was performed in the Chemical Kinetics laboratory, Department of Chemical/Petrochemical Engineering, Rivers State University of Science and Technology.

Fermentation of palmwine: 1.5 liters of palm wine was placed in the fermenter. $6.0 \mathrm{~g}$ of yeast extract (Saccharomyce Cerevisiae) was introduced and stirred. Samples were collected with a syringe into sterile bottles at 2 hours time intervals for analysis of its $\mathrm{pH}$ and concentrations of the substrate, biomass and ethanol product. At the time the largest drop in substrate concentration was observed (the death phase of the yeast), $100 \mathrm{ml}$ of bacteria culture was introduced. Keeping the lid open for oxygen supply, samples were taken in sterile bottles at time intervals of 2 hours and analyzed for Acetic acid and bacteria (biomass) concentration.

\section{ANALYTICAL METHODS AND PROCEDURE}

Measurement of glucose (sustrate) concentration: Different known masses of glucose $(0-0.15 \mathrm{mg})$ were measured, introduced into $100 \mathrm{ml}$ of palm wine and mix thoroughly to obtain various concentrations of glucose. The absorbance of each concentration was measure using a spectrophotometer and a calibration curve produced by plotting a graph of absorbance against concentration. The absorbance of the samples collected at 2 hours interval during the fermentation process were measured and the corresponding mass concentrations of substrate (glucose) in the samples obtained from the calibration curve.

Measurement of ethanol concentration: Different volumes of $98 \%$ ethanol were measured and their corresponding mass obtained using the standard ethanol density of 0.989 (Perry and Don, 1984). 
Am. J. Sci. Ind. Res., 2012, 3(4): 231-240

These volumes were each introduced into $100 \mathrm{ml}$ of palm wine, mixed thoroughly and the absorbance measured using a spectrophotometer. a calibration curve was produced from a plot of absorbance against mass concentration of ethanol.

The absorbance of the samples collected at 2 hours interval during the fermentation process were measured and the corresponding mass concentrations of ethanol in the samples obtained from the calibration curve.

Measurement of biomass - yeast - concentration: Different known masses of dry yeast (Saccharomyce Cerevisiae) were measured, introduced into $100 \mathrm{ml}$ of palm wine and mix thoroughly to obtain various concentrations of dry yeast. The absorbance of each concentration was measure using a spectrophotometer and a calibration curve produced by plotting a graph of absorbance against concentration. The absorbance of the samples collected at 2 hours interval during the fermentation process were measured and the corresponding mass concentrations of biomass in the samples obtained from the calibration curve.

These calibration curves are presented in Figures 1, 2 and 3 respectively.

Measurement of acetic acid concentration: The standard method of Horold et al., (1981) is used in the measurement of the amount of acetic acid. $10 \mathrm{ml}$ samples were collected at 2 hours interval during the acetic acid production and titrated with $0.1 \mathrm{~m}$ sodium hydroxide $(\mathrm{NaOH})$ solution using bromo-methly blue as indicator. The volume of sodium hydroxide at the end of each titration is recorded. The amount (mass) of acetic acid in each sample is obtained using the ratio $1 \mathrm{ml}$ of $0.1 \mathrm{~m} \mathrm{NaOH}=0.006005 \mathrm{~g}$ of Acetic acid. The concentration of acetic acid in each sample is subsequently obtained from the mass of acetic acid and volume of sample.

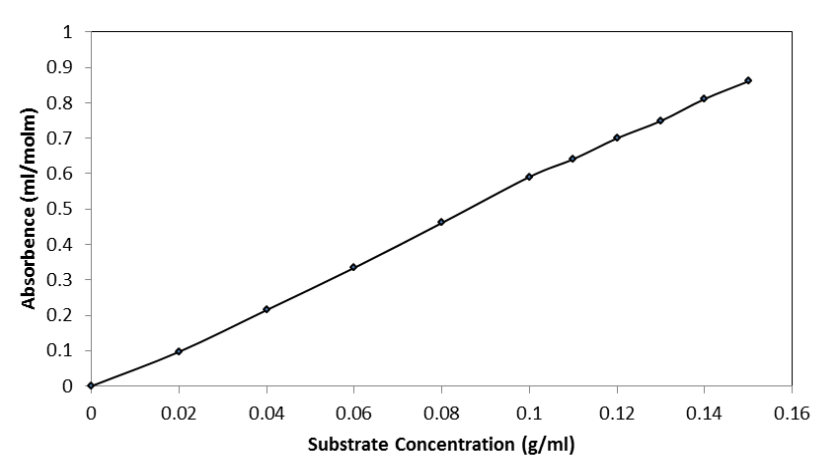

Figure 1: Calibration curve for Determining Substrate Concentration

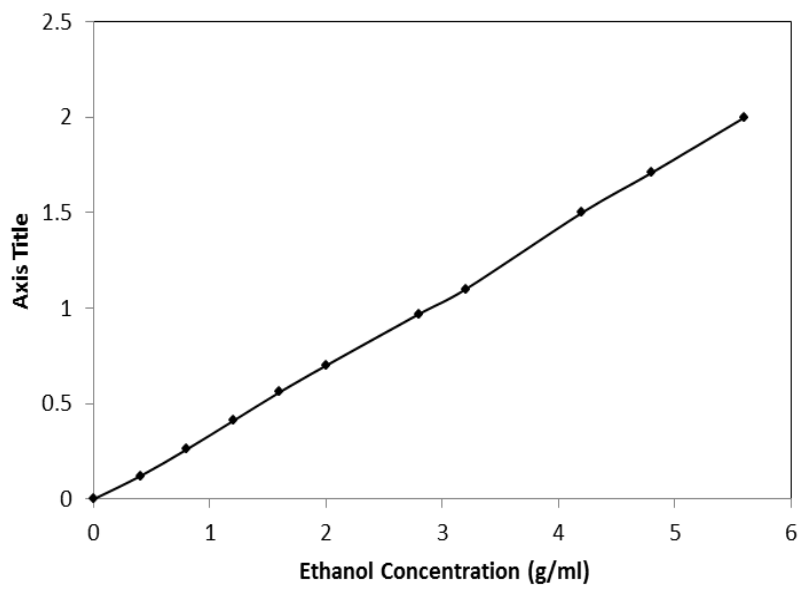

Figure 2: Calibration curve for Determining Ethanol Concentration

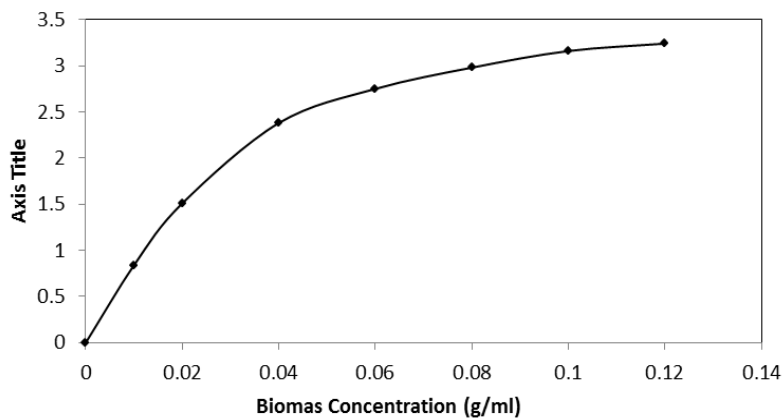

Figure 3: Calibration curve for Determining Biomas Concentration

Kinetic model: Several models have been proposed to describe the kinetics of fermentation; In general, fermentation kinetic model can be subdivided into a growth, a substrate and a product model (Marin, 199). The rate of cell growth is characterized by a series of phases starting with a lag phase during which little or no increase in microbial density occurs, followed by a period of exponential growth which continues until the food supply becomes exhausted. It then enters a stationary phase during which the 
organisms cease to grow and then the final decline phase in which the active mass diminishes as the cell population dies away (Levenspiel, 1999). Substrate inhibition occurs generally at high substrate concentration. It is primarily caused by more than one substrate molecule binding to an active site and/or often by different parts of the substrate molecules binding to different sub-sites within the substrate binding site (Agarwal et al., 2009).

Various substrate inhibition models used to explain cell growth kinetics have been reviewed by Caro et al., (1991), De Vasconcelos et al., (2004), Ciani, et al., (2006), Daawson and Boopathy, (2007) and Agarwal et al., (2009). Among these models describing the growth kinetics of microorganisms, the Monod's model has been found to be the most simple and fundamental model proposed to explain microbial growth and predicts a proportional relationship between specific growth rate and initial substrate concentration Agarwal et al., (2009).

The Monod's growth model was therefore chosen to describe the growth kinetics of palm wine fermentation in this work and incorporating an appropriate inhibition term. The Monod's saturationisotherm type equation which relates the growth rate of a micro-organism culture (biomas) to the prevailing feed concentration (substrate) is expressed as:

$R_{B}=\frac{R_{\max } C_{S}}{K_{S}+C_{S}}$

Where:

$$
\begin{aligned}
& \mathrm{R}_{\max }=\text { Maximum specific growth rate. } \\
& \mathrm{K}_{\mathrm{S}}=\text { Monod constant. } \\
& \mathrm{C}_{\mathrm{S}}=\text { Substrate concentration }
\end{aligned}
$$

Levenspiel, (1999) gave a simple substrate inhibition factor as:

$$
R_{\text {obs }}=k\left(1-\frac{c_{R}}{c_{R}^{*}}\right)^{n}
$$

Where $\mathrm{k}=$ inhibition constant

$C_{R}^{*}=$ the product concentration where all cell activity stops.

$\mathrm{n}$ is an empirical constant.

Introducing this effect, the Monod's rate equation becomes:
$R_{B}=k\left(1-\frac{c_{R}}{c_{R}^{*}}\right)^{n} \frac{c_{S}}{K_{S}+c_{S}}$

For the glucose to ethanol fermentation, typical inhibition parameters (Opara, 2002) are

$$
\mathrm{n}=0.5 \text { and } \mathrm{C}_{\mathrm{R}}{ }^{*}=93 \mathrm{~g} / \mathrm{ml}
$$

Levenspiel, (1999) derived the relationships between the rate of substrate utilization and product formation to the rate of microbial/cell growth using an appropriate yield coefficient.

RATE OF SUBSTRATE UTILIZATION (-RS

$$
-\mathrm{R}_{\mathrm{S}}=-\mathrm{R}_{\mathrm{B}} \mathrm{Y}_{\mathrm{S} / \mathrm{B}}
$$

RATE OF PRODUCT FORMATION (ETHANOL AND ACETIC ACID) (-RP)

$$
-\mathrm{R}_{\mathrm{p}}=-\mathrm{R}_{\mathrm{B}} \mathrm{Y}_{\mathrm{P}_{\mathrm{B}}}
$$

Substituting the rate of microbial/cell growth equation (1) into equations (4) and (5) gives the rate of substrate utilization and product formation as:

$-\mathrm{R}_{\mathrm{S}}=-k\left(1-\frac{c_{R}}{c_{R}^{*}}\right)^{n} \frac{c_{S}}{k_{S}+c_{S}} \mathrm{Y}_{\mathrm{S}_{\mathrm{B}}}$

$-\mathrm{R}_{\mathrm{p}}=-k\left(1-\frac{c_{R}}{c_{R}^{*}}\right)^{n} \frac{c_{S}}{k_{S}+c_{S}} \mathrm{Y}_{\mathrm{p}_{/ \mathrm{B}}}$

The yield coefficient was used to relate the quantities of materials consumed and produced during the fermentation process. Hence the product concentration can be written in terms of the yield coefficients and the biomas or substrate concentration as:

$$
\begin{aligned}
& C_{P}=Y_{P / B} C_{B} \\
& C_{P}=Y_{P / S} C_{S}
\end{aligned}
$$

Substituting equation (8) and (9) into equations (3) and (6) yields:

$$
\begin{gathered}
R_{B}=k\left(1-\frac{Y_{P_{B}} C_{B}}{c_{P}^{*}}\right)^{n} \frac{c_{S}}{K_{S}+c_{S}} \\
-\mathrm{R}_{\mathrm{S}}=-k\left(1-\frac{{ }_{P_{S_{S}}} c_{S}}{c_{P}^{*}}\right)^{n} \frac{c_{S}}{K_{S}+C_{S}} \mathrm{Y}_{S_{\mathrm{B}}}
\end{gathered}
$$


Batch reactor model: The fermentation process occurs in a bioreactor and was modeled as a batch reactor. The continuity equation of mass was applied to the batch reactor to develop mathematical equations that were used to monitor the flow of mass (the rate of substrate (glucose) utilization, the rate of biomass formation (yeast and bacteria) and the rate of product formation (ethanol and acetic acid)) of the fermentation process as follows:

For cell/Biomas:

The cell death rate is accounted for using the equation (Opara 2002):

$R_{d}=K_{d} C_{X}$

Amount of biomas formed with time is:

$$
\frac{d C_{X}}{d t}=R_{B} C_{X}-R_{d}
$$

For substrate:: In addition to the consumption of substrate to produce new cells (biomass formation), part of the substrate is usually used to produce maintenance energy required to maintain a cell's daily activity. The rate of substrate consumption for maintenance is given by the expression (Opara 2002):

$$
R_{s m}=M C_{X}
$$

The corresponding maintenance utilization term (M) is given by the expression:

$M=\frac{\text { Mass of substrate consumed for maintainance }}{\text { Mass of cells formed }}$

Amount of substrate utilized with time is:

$$
\frac{d C_{S}}{d t}=R_{S} C_{X}-R_{S M}
$$

For product:

Amount of products formed with time is:

$$
\frac{d C_{P}}{d t}=R_{P} C_{X}
$$

Substituting equations (10) and (12) into (13); equations (11) and (14) into (16); equation (7) into (17) gives:

$$
\frac{d c_{X}}{d t}=k\left(1-\frac{{ }_{P_{P_{X}}} C_{X}}{C_{P}^{*}}\right)^{n} \frac{c_{S}}{K_{S}+C_{S}} C_{X}-K_{d} X
$$

$$
\begin{gathered}
\frac{d C_{S}}{d t}=-k\left(1-\frac{Y_{P} / S}{C_{P}^{*}}\right)^{n} \frac{C_{S}}{K_{S}+C_{S}} \mathrm{Y}_{S / \mathrm{B}} C_{X}-M X \\
\frac{d C_{P}}{d t}=-k\left(1-\frac{C_{P}}{C_{P}^{*}}\right)^{n} \frac{C_{S}}{K_{S}+C_{S}} \mathrm{Y}_{P_{/}} C_{X}
\end{gathered}
$$

Equations (18), (19), (20) are the model equations for the rates of biomass formation, substrate utilization and product formation.

The energy equation: The continuity equation of energy was applied to the batch reactor to develop mathematical equations that were used to monitor the temperature progression of the fermentation process.

$$
\frac{d T}{d t}=\frac{R_{P} \Delta H_{R}}{\rho C_{P E}}
$$

Equation (21) is the model equation describing the temperature progression with time in the bioreactor.

\section{KINETIC PARAMETER ESTIMATION}

The Mono's equation $R_{B}=\frac{R_{\max } C_{S}}{K_{S}+C_{S}}$ used to represent the kinetic model of this process was rewritten in the form of the equation of a straight line $y=m x+c$

as: $\frac{1}{R_{B}}=\left(\frac{K_{S}}{R_{\max }}\right) \frac{1}{C_{S}}+\frac{1}{R_{\max }}$ where $\mathrm{m}$ the slope of the equation corresponds to $\frac{K_{S}}{R_{\max }}$ and c the intercept corresponds to $\frac{1}{R_{\max }}$. The concentrations of the substrate, biomass and product $\left(\mathrm{H}_{\mathrm{i}}\right)$ and the corresponding rates of the fermentation process $(R)$ obtained from the experiment are used to plot a graph of $\frac{1}{R_{B}}$ against $\frac{1}{C_{S}}$ known as the line-weaver burk plot. The Newton non-linear repression method of polymath was used to fit a linear equation to the lineweaver burk plot generated. The slope and intercept from the equation are equated to $\frac{K_{S}}{R_{\max }}$ and $\frac{1}{R_{\max }}$ respectively, from which $K_{S}$ and $R_{\max }$ values were obtained.

Solution technique for model equations: The model equations obtained were a set of coupled linear ordinary differential equations. These sets of ordinary differential equation (ODE) were solved numerically using the $4^{\text {th }}$ order Runge-Kutta algorithm. A visual basic program was written to implement this algorithm. The program predicted the 
substrate, biomass and product concentration and temperature of the bioreactor in the course of the fermentation process.

\section{RESULTS AND DISCUSSIONS}

Determination of kinetic parameters: The constants in the kinetic rate equation (the mono's equation) for ethanol and acetic acid production were determined from Figures (4) and (5).

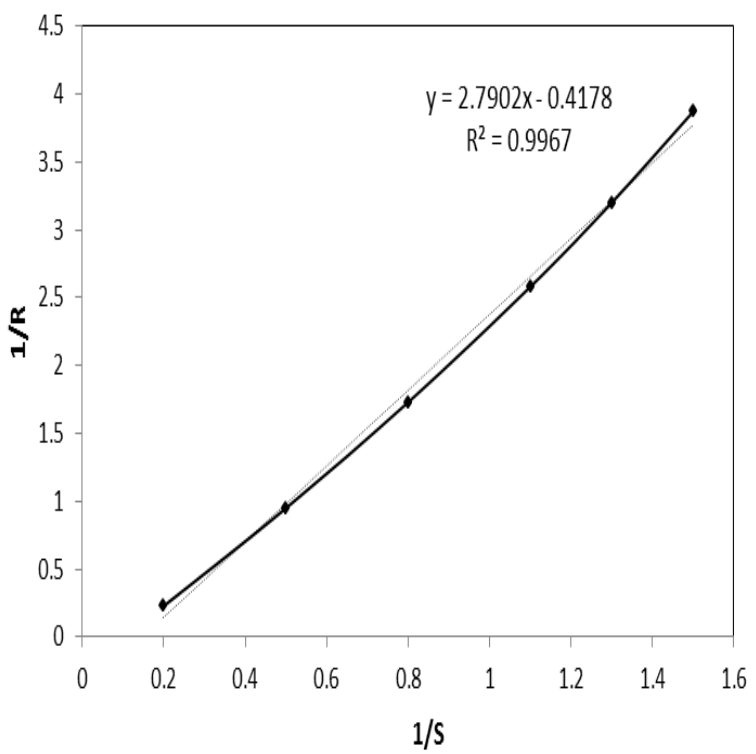

Figure 4: Determination of Kinetic Parameters for Ethanol Production.

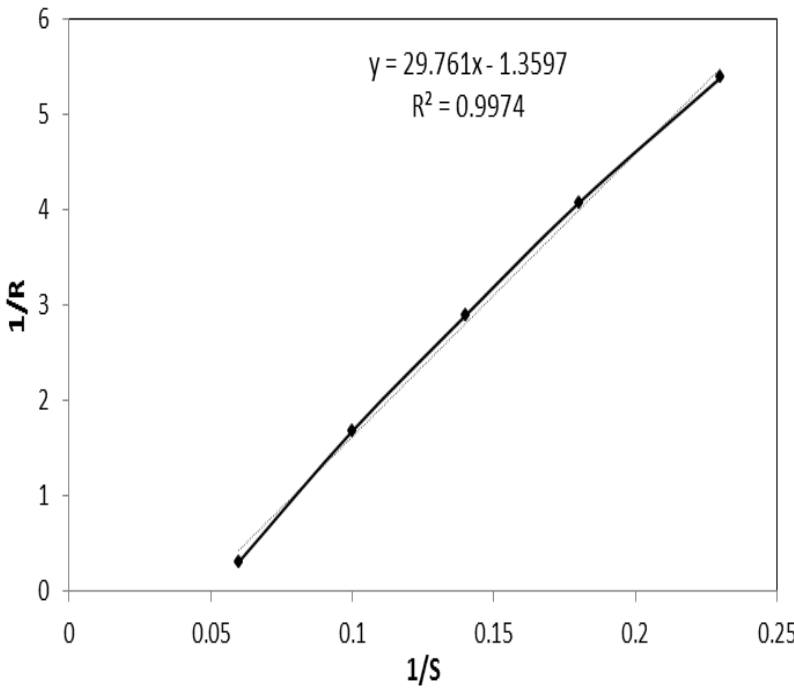

Figure 5: Determination of Kinetic Parameters for Acetic Acid Production.

The rate equation obtained after substituting the kinetic constant for ethanol and acetic acid production are:

For Ethanol Production:

$R_{E t}=\frac{2.3981 C_{s}}{6.6907-C_{s}}$

For Acetic Acid Production:

$R_{A A}=\frac{0.7358 C_{g}}{21.8974-C_{g}}$

\section{EXPERIMENTAL AND MODEL RESULTS}

Table 1: Comparison of Experimental Results and Model Prediction for Ethanol and Acetic Acid Production.

\begin{tabular}{|c|c|c|c|c|c|c|}
\hline \multirow[t]{2}{*}{ COMPONENT } & \multicolumn{3}{|c|}{ ETHANOL PRODUCTION } & \multicolumn{3}{|c|}{ ACETIC ACID PRODUCTION } \\
\hline & $\begin{array}{l}\text { EXPERIMENT } \\
\text { (Conc. g/ml) }\end{array}$ & $\begin{array}{l}\text { MODEL (Conc. } \\
\mathrm{g} / \mathrm{ml} \text { ) }\end{array}$ & DEVIATION \% & $\begin{array}{l}\text { EXPERIMENT } \\
\text { (Conc. g/ml) }\end{array}$ & $\begin{array}{l}\text { MODEL (Conc. } \\
\mathrm{g} / \mathrm{ml} \text { ) }\end{array}$ & DEVIATION \% \\
\hline BIOMAS & 2.51 & 2.35 & 0.068 & 2.10 & 2.27 & 0.075 \\
\hline PRODUCT & 7.37 & 7.56 & 0.025 & 17.08 & 16.95 & -0.006 \\
\hline
\end{tabular}

Table I shows the substrate, biomass and product (ethanol and acetic acid) concentration at the end of the fermentation period as predicted by the model in comparison with values obtained from the experiment. This results show deviations ranging from 0.025 to $0.402 \%$ for ethanol and 0.006 to
$0.075 \%$ for acetic acid production. The experimental trends of the substrate, biomass and products (ethanol and acetic acid) concentration from beginning to end and model predictions are shown in Figures (6) and (7), while the model prediction of the 
Am. J. Sci. Ind. Res., 2012, 3(4): 231-240

temperature progression during the fermentation process is shown in Figure 8.

In the fermentation process, the microorganisms/biomass (yeast and bacteria) feed on the substrate (acts as the catalyst) to produce the products (ethanol and acetic acid), thus as fermentation proceeds, the micro-organism concentration initially increased minimally, followed by a leap (exponential growth), then the concentration became constant towards the end (stationary phase) as the substrate is used up (substrate concentration decreases). There was a steady and continuous increase in product concentration while substrate concentration decreased steadily. However for acetic acid production there was minimal decrease in substrate concentration during the fermentation process. These trends are similar to those obtained by Odunfa, (1985) and Sinclair and Kristiansen, (1987) which are the expected trends for a microbial process and were also accurately predicted by the models developed. Figures (6) and (7) also show the close match between the experimental results and model predictions; this shows the accuracy of the models developed for the palm wine fermentation process.

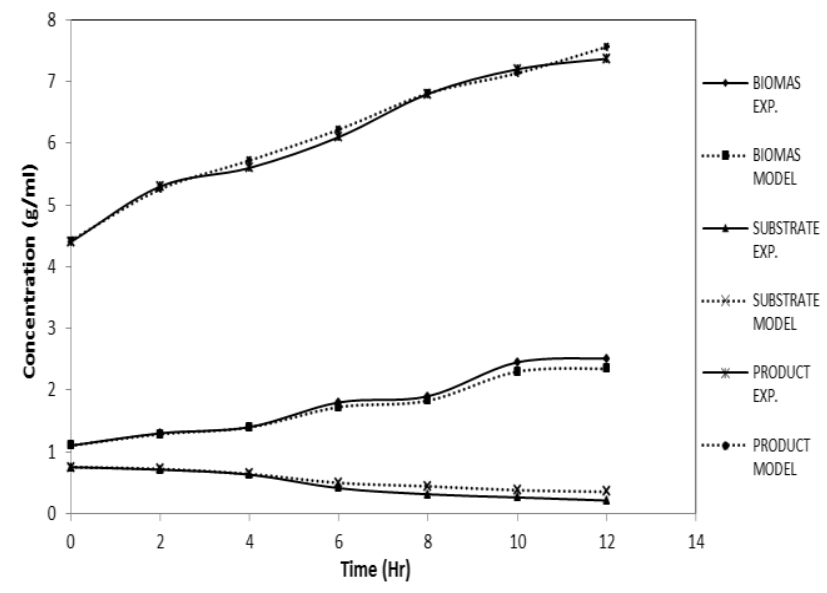

Figure 6: Experimental and Model Results for concentration of Substrate utilized, Biomas and Ethanol Produced

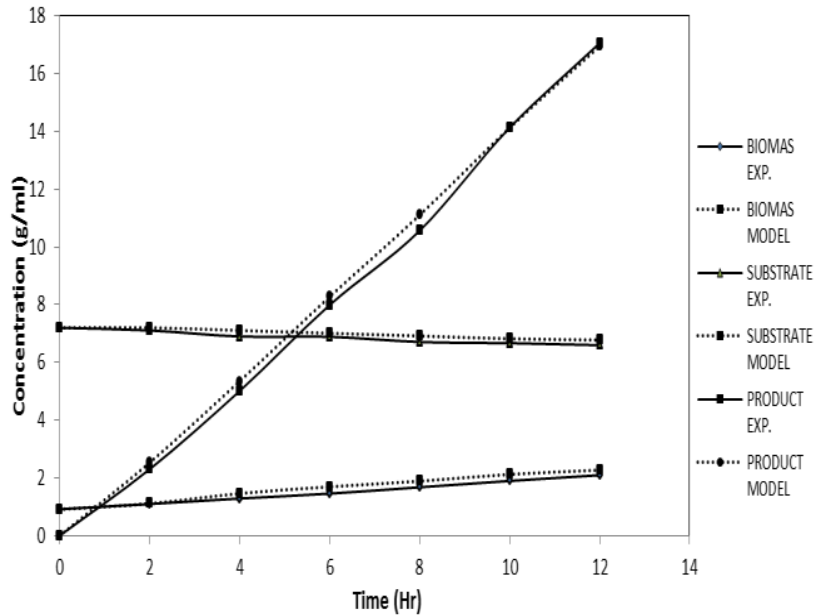

Figure 7: Experimental and Model Results for concentration of Substrate utilized Biomas and Acetic Acid produced

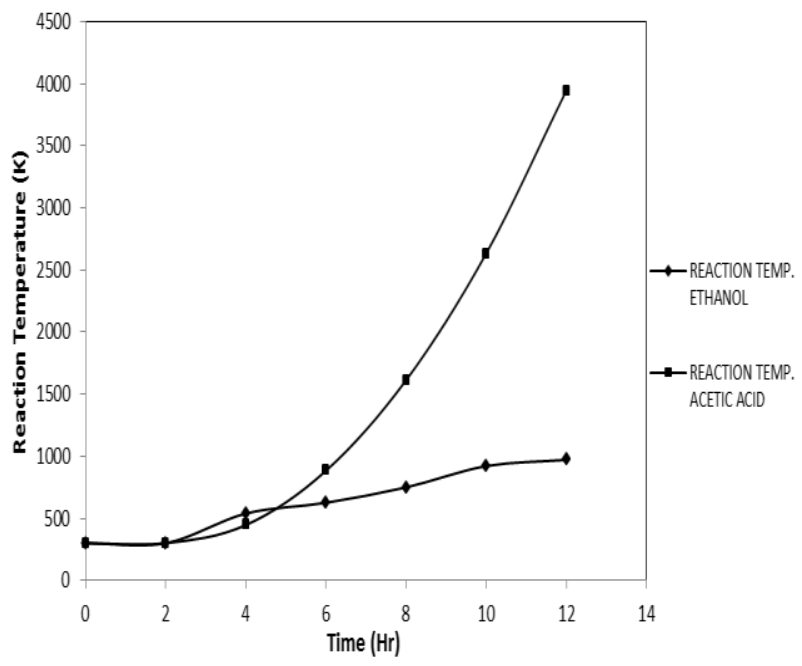

Figure 8: Reaction Temperature for Ethanol and Acetic acid Production

The temperature progression of the fermentation process for the production of ethanol and acetic acid are shown in Figure 8 . The model equation predicted a sharp increase in reacction temperature with time for ethanol production and a gradual minimal increase in reaction temperature for ecetic acid production, confirming that the reactions are exothermic. 
Am. J. Sci. Ind. Res., 2012, 3(4): 231-240

Model simulation: The effects of initial substrate and biomass concentration on the fermentation process were investigated.

Effect of substrate concentration: The effect of the initial substrate concentration on the biomass, ethanol and acetic acid produced during the fermentation process are shown in Figure 9. Ethanol production increased greatly while acetic acid production was constant with increase in initial substrate concentration. Biomass production also remained virtually constant with increase in initial substrate concentration. This is in conformity with findings in the works of Thatipamala et al., (1992) and Volesky and Votruba (1992) that at high substrate concentration, a constant and maximum specific growth rate is reached.

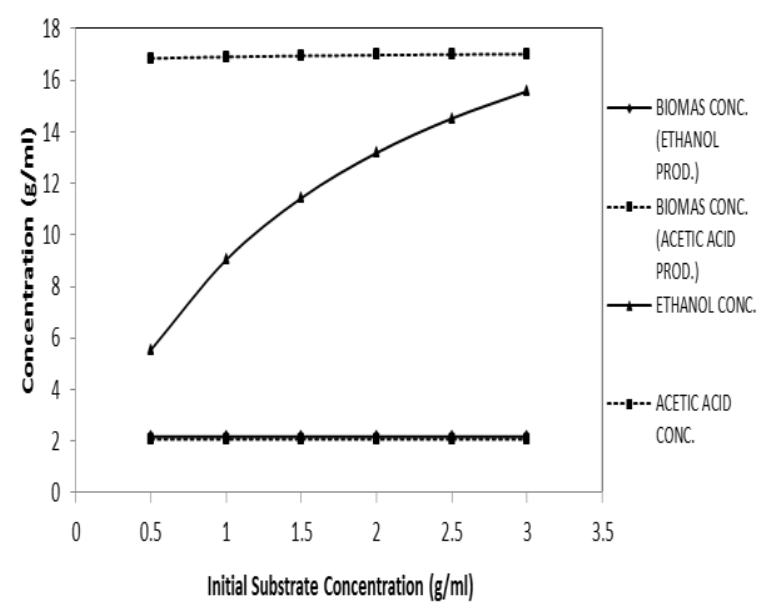

Figure 9: Effect of Initial Substrate concentration on Biomas, Ethanol and Acetic Acid production

The model equations also predicted a steady increase in reaction temperature for ethanol production due to increased rate of reaction, confirming that reaction is exothermic (Phisalaphong et al., 2006), while reaction temperature for acetic acid production was constant due to the almost constant rate of reaction. These trends are shown in Figure 10.

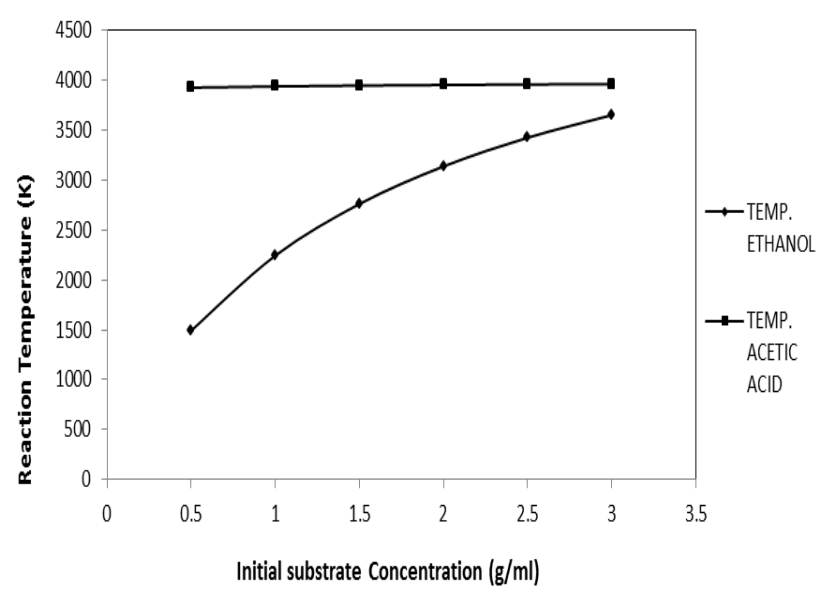

Figure 10: : Effecct of Initial Substrate Concentration on Reaction Temperature for Ethanol and Acetic acid production

Effect of initial biomas concentration: The effect of the initial biomass concentration on the substrate utilization, ethanol and acetic acid produced during the fermentation process are shown in Figure 11. As the initial biomass concentration is increased, more biomass (micro-organism/catalyst) are available to feed on substrate, hence rate of reaction increases resulting in an increase in product concentration (ethanol and acetic acid) and a decrease in substrate concentration. This is in agreement with the works of Sablayrolles, (2009). The increase in reaction rate also results in an increase in reaction temperature for both ethanol and acetic acid production since both are exothermic processes. These trends are shown in Figure 11 and Figure 12.

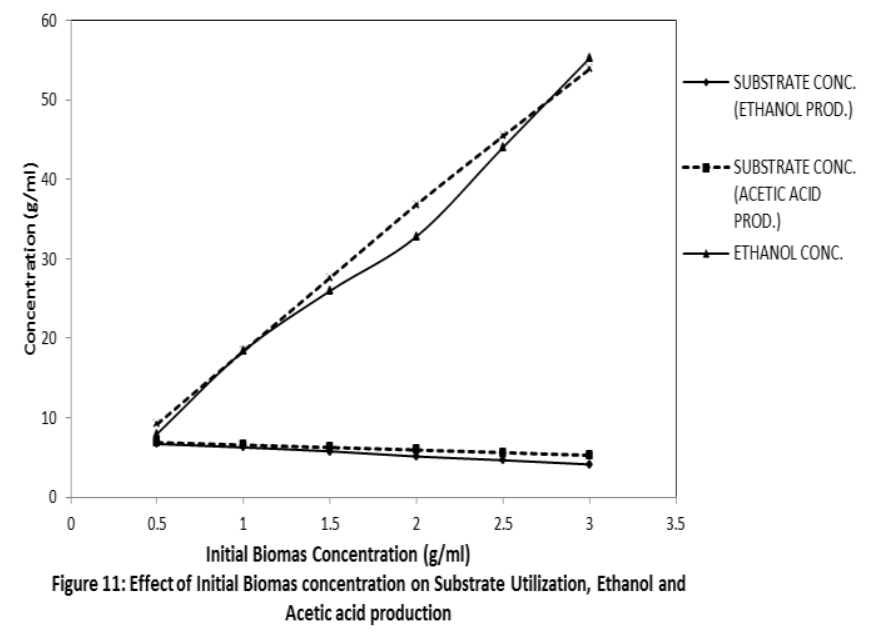




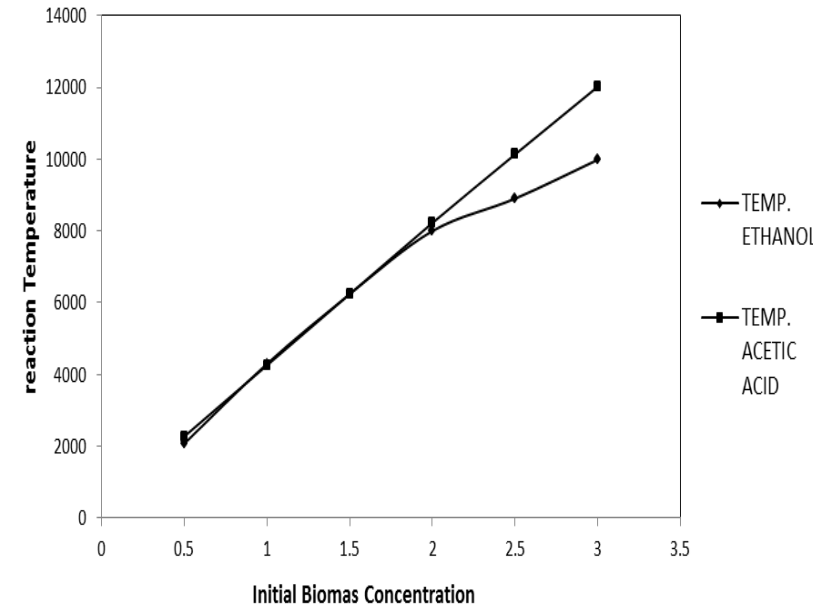

Figure 12: Effecct of Initial Biomas Concentration on Reaction Temperature for Ethanol and Acetic acid production

\section{CONCLUSION}

A laboratory scale fermentation of palm wine to ethanol and acetic acid was performed. The monod's equation was used to approximate the reaction kinetics of the fermentation of palm wine to ethanol using yeast and acetic acid using lactobacillus. The constants in the monod's equation were successfully obtained using the experimental data from the fermentation process.

Mathematical models for the batch reactor were also developed that accurately predicted the concentration of substrate utilized, biomass, products produced and time-temperature progression within reactor. The reaction rates were used to solve the model equations developed. The model predictions compare very favorably with laboratory experimental results, hence models developed were used to predict the rates of substrate utilization, product formation and biomass formation of the fermentation process and simulate the bioreactor. The effects of initial substrate and biomass concentration were investigated.

\section{NOMENCLATURE}

$\mathrm{R}_{\max }=$ Maximum specific growth rate.

$\mathrm{K}_{\mathrm{S}}=$ Monod constant.

$\mathrm{C}_{\mathrm{S}}=$ Substrate concentration

$\mathrm{k}=$ inhibition constant

$C_{R}^{*}=$ the product concentration where all cell activity stops.

$\mathrm{n}$ is an empirical constant.
$\mathrm{C}_{\mathrm{i}}=$ Biomas $(\mathrm{B}, \mathrm{x})$, Substrate $(\mathrm{s})$ or product $(\mathrm{p})$ concentration.

$\mathrm{R}_{\mathrm{i}}=$ rate of formation or utilization of $\mathrm{i}$

$M=$ Maintenance utilization term

$Y_{i j j}=$ Yield coefficient of $i$ with respect to $j$

$\mathrm{K}_{\mathrm{d}}=$ Death constant

$\mathrm{t}=$ Time

$\mathrm{T}=$ Temperature

$\Delta \mathrm{H}_{\mathrm{R}}=$ Heat of Reaction

$\rho$ = Density

$C_{p}=$ Specific Heat capacity of Reaction

\section{REFERENCES}

Adams, O. and Moss, K. (1995) Handbook of Indigenous Fermented Foods, Marcel Decker Inc., New York.59-60.

Agarwal, R., Mahanty, B. and Venkata Dasu, V., (2009), Modeling Growth of Cellulomonas cellulans NRRL B 4567 under Substrate Inhibition during Cellulase Production, Chemical Biochemical Engineering, Q. 23 (2) 213-218.

Agu, R. C., Anyanwu, T. U. and Onwumelu, A. H. (1993), Uses of high ethanolOresistant yeast isolates from Nigerian palm wine in large beer brewing. World J. Microbio. and Biotechnol. 9: 660-661.

Akpan, U. G., Kovo, M., Abdullahi, M. and ljah, J. J. (2005), The production of ethanol from maize cobs and groundnut shells, Australian journal of technology. 9(2), 106-110.

Board. M. (1983), Fermented Beverage Production, Blackie Academic and Professional press London.67-96

Caro, I., Perez, L. and Cantero, D., (1991), Development of a kinetic model for the alcoholic fermentation of must, Biotechnol. Bioeng, 38, 742-748.

Ciani, M., Beco, L. and Comitini, F., (2006), Fermentation behaviour and metabolic interaction of multistarter wine yeast fermentations, Int $\mathrm{J}$ of Food Microbiol, vol. 108, 239-245.

Dawson, L. and Boopathy, R., (2007), Use of post-harvest sugarcane residue for ethanol production, Biores. Technol., vol. 98, 1695 - 1699. 
De Vasconcelos, J. N., Lopes, C. E. and De Franca, F. P., (2004), Continuous ethanol production using yeast immobilized on sugar-cane stalks, Brazilian J. Chem. Engr. 21(3): 357-365.

Esechie, H. A. (1979), Fermentation Studies on Nigeria Palm wine, Nigeria Agricultural Journal 16, 96102.

Horold, H, Smith, J., Octave, L. (1981), Classification of Foods, Journal of Food Science Technology 4 1321.

Harrigan, W. F. and Mccane, M. E., (1990), Laboratory Method in food and diary Microbiology Academic press publisher, $8^{\text {th }}$ Ed. $136-138$.

Levenspiel, O. (1999), $3^{\text {rd }}$ Edition, Chemical Reaction Engineering, John Wiley \& sons, USA, 623-640.

Marín, M. R., (1999), Alcoholic fermentation modeling: current state and perspectives. Am. J. Enol. Vitic., 50(2), 166-178.

Odunfa, S. A. (1985), Microbiology of fermented food. Elsevier Applied Science Publishers UK 45-47.

Okafor, N. (1975), Preliminary Microbiological studies on the preservation of palm wine, Journal Application act 81 .

Okafor, N. (1990), Traditional Alcoholic Beverage of tropical Africa; strategies for scale up, Process Biochemistry Journal, 205-217.
Opara, C. C. (2002), Biochemical and Microbiological Engineering, Chijioke consultant Publication Ikenegbu, owerri, 144-146.

Perry, R. H. and Don, G. (1984), Handbook of Chemical Engineering, McGraw-Hill, New York.

Phisalaphong, M., Srirattana, N. and Tanthapanichakoon, W. (2006), Mathematical modeling to investigate temperature effect on kinetic parameters of ethanol fermentation. Biochem. Eng. J. 28:36-43.

Sablayrolles, J. M. (2009), Control of alcoholic fermentation in winemaking: Current situation and prospects. Food Research International, 42(4), 418-424.

Sinclair, C. G. and Kristiansen, B. (1987), Fermentation kinetics and modeling, Taylor \& Francis: New York.

Thatipamala, R., Rohani, S. and Hill, G. A. (1992), Effects of high product and substrate inhibitions on the kinetics and biomass and product yields during ethanol batch fermentation, Biotechnology and Bioengineering, vol. 40, 289-297.

Volesky, B. and Votruba, H. (1992), Modeling and Optimization of Fermentation Processes, Elsevier, Amsterdam.

Wang, D., Xu, Y., Hu, J. and Zhao, G., (2004), Fermentation Kinetics of Different Sugars by Apple Wine Yeast Saccharomyces cerevisiae, J. Inst. Brew. 110(4), 340-346. 